\title{
Laminar Smoke Points of Nonbuoyant Jet Diffusion Flames
}

\author{
P. B. SUNDERLAND, S. MORTAZAVI, and G. M. FAETH* \\ Department of Aerospace Engineering, The University of Michigan, Ann Arbor, MI 48109-2140 \\ D. L. URBAN \\ Microgravity Science Section, Suerdrup Technology, Inc., Brook Park, OH 44142
}

\section{INTRODUCTION}

The laminar smoke point properties of jet diffusion flames - the luminous flame length, the residence time, and the fuel flow rate, at the onset of soot emission from the flames-have proven to be useful global measures of the soot properties of nonpremixed flames. These measures provide a means to rate several aspects of sooting properties: the relative tendency of various fuels to emit soot from flames [1-4]; the relative effects of fuel structure, flame temperature, and pressure on the soot properties of flames [5-10]; and the relative levels of continuum radiation from soot in flames [11-13]. Measurements of laminar smoke point properties generally are based on - round buoyant jet diffusion flames, surrounded by a coflowing air (or oxidant) stream to prevent the flame pulsations characteristic of buoyant diffusion flames in still environments. Laminar smoke point properties found from this configuration are relatively independent of burner diameter and coflow velocities, which has helped to promote their acceptance as global measures of soot properties [9]. However, recent studies suggest potential for fundamental differences between the laminar smoke point properties of buoyant and nonbuoyant flames $[9,14]$. Thus, the overall objective of the present investigation was to measure the laminar smoke point properties of

\footnotetext{
* Corresponding author: 218 Aerospace Engineering Bldg., The University of Michigan, Ann Arbor, MI 48109-2140. Tel.: 313-764-7202, FAX: 313-763-0578
}

nonbuoyant flames, due to their relevance to many industrial processes where effects of buoyancy are small.

The potential differences between the laminar smoke point properties of buoyant and nonbuoyant flames can be attributed mainly to the different hydrodynamic properties of these flames [14]. This is illustrated in Fig. 1, where some features of axisymmetric buoyant and nonbuoyant laminar diffusion flames are plotted as a function of streamwise and radial distance, $x$ and $r$, normalized by the flame length and jet exit diameter, $L$ and $d$. The results for the buoyant flame are based on the measurements of Santoro et al. [15-17] while the results for the nonbuoyant flame are based on predictions $[18,19]$. The region bounded by fuel-equivalence ratios, $\phi=1$ and 2 , is marked on the figures because these conditions are associated with processes of soot nucleation and growth [9]. The dividing streamline, or locus of conditions where the radial velocity $v=0$, also is shown on the plots. In particular, soot particles are too large to diffuse like gas molecules so that they are convected by gas velocities aside from minor effects of thermophoresis; therefore, soot particles tend to convect toward the dividing streamline, that is, radial velocities inside and outside the dividing streamline are positive and negative, respectively. Due to flow acceleration within buoyant flames, the dividing streamline moves toward the flame axis with increasing streamwise distance and generally lies inside the soot nucleation and growth region. In contrast, due to flow deceleration in nonbuoyant flames, the 

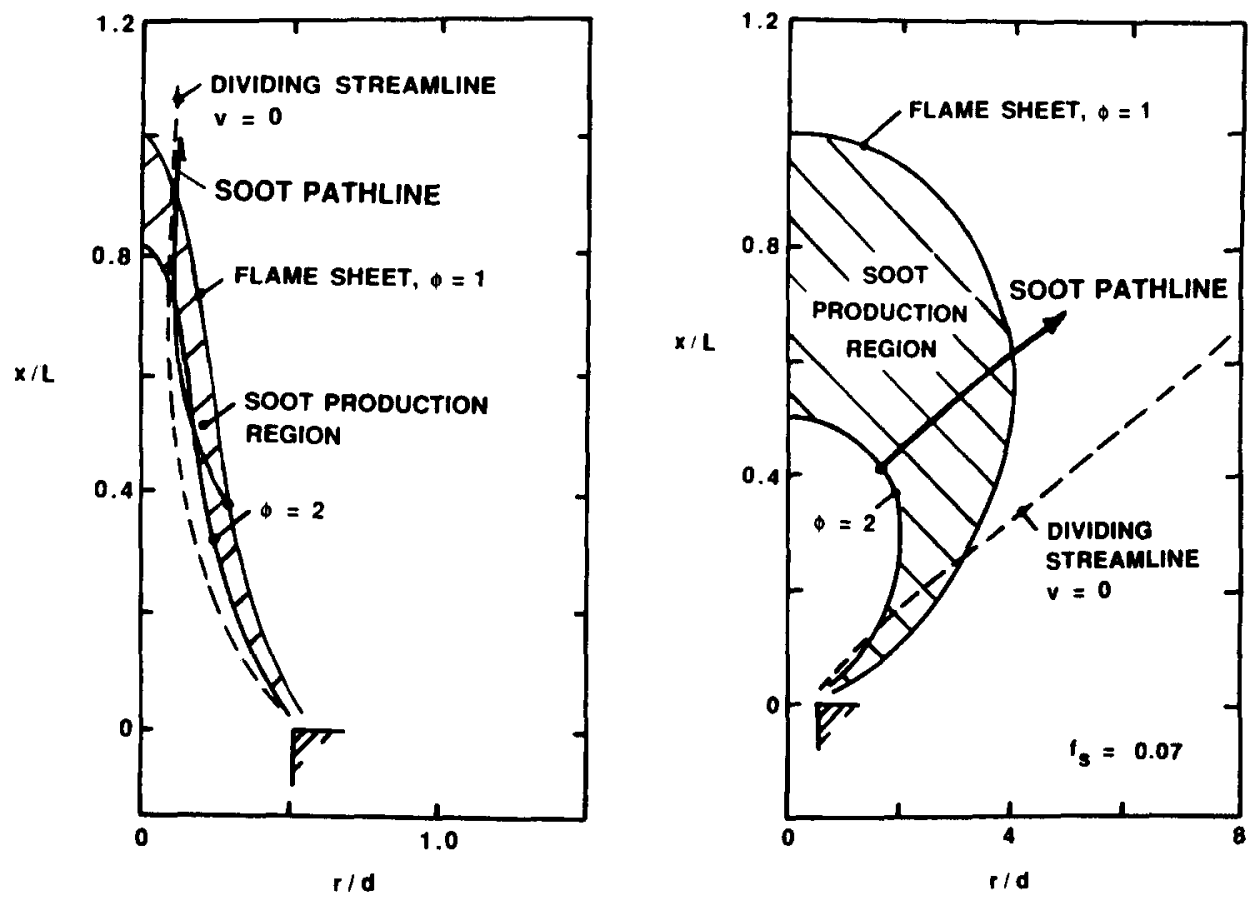

Fig. 1. Sketch of soot paths in buoyant and nonbuoyant jet diffusion flames.

dividing streamline moves away from the flame axis with increasing streamwise distance and generally lies outside the soot nucleation and growth region.

Recalling that initial soot emission (which generally defines laminar smoke point properties) is associated with the region near the flame tip [15-17], the paths of soot in the tip region are illustrated in Fig. 1 for buoyant and nonbuoyant flames. For buoyant flames, soot nucleates near the outer boundary of the soot nucleation and growth region (ca. $\phi=1$ ) and then moves radially inward toward cooler and less reactive conditions at higher fuel equivalence ratios for a time before finally crossing the flame sheet near its tip within an annular soot layer in the vicinity of the dividing streamline. In contrast, soot particles responsible for the initial emission of soot in nonbuoyant flames nucleate at relatively high equivalence ratios near the inner boundary of the soot nucleation and growth region (ca. $\phi=2$ ), and then are drawn directly toward and through the flame sheet so that they experience a monotonic reduction of fuel equivalence ratio throughout their lifetime. Additionally, velocities along these two different soot paths pro- gressively increase for buoyant flames and progressively decrease for nonbuoyant flames. This implies that the ratios of residence times for soot nucleation and growth to residence times for soot oxidation generally are smaller for nonbuoyant than buoyant flames [14-17]. Finally, even the existence of global laminar smoke point properties has been questioned for nonbuoyant diffusion flames, because nonbuoyant jet diffusion flames have residence times that are independent of flame length under the boundary layer approximations, unlike buoyant flames where residence times increase with increasing flame length [9]. Clearly, the soot nucleation, growth, and oxidation environment of buoyant and nonbuoyant flames is quite different, providing ample reasons for different laminar smoke point properties as well. Thus, study of effects of buoyancy on laminar smoke point properties should help to provide a better understanding of soot processes in diffusion flames.

Prior to this work, no experiments have been reported to assess these potential effects of buoyancy on laminar smoke point properties. Thus, the present objective was to measure the laminar smoke point flame lengths and resi- 
dence times of nonbuoyant flames. The scope of the study was limited to round ethylene and propane jet diffusion flames burning in slightly vitiated air at pressures of $0.5-2.0$ atm. A low-gravity test environment was used to obtain nonbuoyant flames at the small flow velocities characteristic of laminar smoke point conditions.

\section{EXPERIMENTAL METHODS}

\section{Apparatus}

The experiments were conducted using the NASA KC-135 low-gravity facility. This aircraft flies parabolic trajectories to provide roughly $20 \mathrm{~s}$ at low gravity $\left(\sim 10^{-2} \mathrm{~g}\right.$ ) conditions. The flames were observed within a cylindrical chamber having an internal volume of roughly $87 \mathrm{~L}$. The chamber could be evacuated in flight to roughly 0.36 atm by venting overboard, and was refilled with air stored under pressure in cylinders so that levels of vitiation were limited to less than $10 \%$ oxygen consumption by volume. The chamber had two windows and an interior light so that soot emission could be observed. The chamber pressure was recorded using an absolute pressure transducer.

Three round burners, having burner exit diameters of $1.6,2.7$, and $5.9 \mathrm{~mm}$, were studied. The outside surfaces of the burner tubes had a $30^{\circ}$ chamfer at the exit, to minimize disturbances of the air entrained into the flames. The fuel flow passage had a constant diameter section with a length-to-diameter ratio of 20:1 to yield fully developed laminar pipe flow at the burner exit. Fuel was delivered from storage bottles through solenoid valves and a needle metering valve to the plenum of the fuel port. The flames were ignited using a retractable hot wire coil near the burner exit.

\section{Instrumentation}

The appearance of the flames was recorded by a color video camera. This allowed postflight determination of flames disturbed by departures from the parabolic flight path, so that observations at these conditions could be eliminated. The video records also were used to measure flame lengths, which were taken to be the lengths of the visible luminous portion of the flames. Flame lengths were found by averaging the video records when fully developed flame shapes were reached, which typically required roughly $2 \mathrm{~s}$. Sooting conditions were found by visual observation of the flames, based on the appearance of a dark soot streak projecting from the flame tip. The chamber pressure and the observations of soot emission from the flames were recorded orally by two observers at different view ports using the audio channel of the video recorder.

The flame lengths measured at the onset of sooting actually were flame luminosity lengths, which is similar to the definition used for the laminar smoke point flame lengths of buoyant laminar jet diffusion flames [1-12]. Due to the presence of the soot oxidation region at fuellean conditions, however, the luminosity length is longer than the conventional flame length where stoichiometric conditions are reached at the flame axis. Fortunately, the ratios of the conventional to luminous flame lengths at the laminar smoke point are similar for nonbuoyant and buoyant flames, ca. $0.6[15-18,20,21]$. Thus, the luminous laminar smoke point flame length provides a reasonable basis to compare the sooting properties of nonbuoyant and buoyant flames.

Experiments for roughly ten flight parabolas were used to find the laminar smoke point luminosity length for a given fuel, burner diameter, and pressure. Based on the accuracy of flame luminosity length determination, potential errors due to acceleration-induced flame tilt along the camera axis and the range of conditions between nonsooting and sooting flames, the experimental uncertainties (95\% confidence) of the laminar smoke point flame luminosity lengths are estimated to be less than $15 \%$. The measurements were repeatable within this range.

\section{THEORETICAL METHODS}

Laminar smoke point residence times are a useful measure of the sooting properties of a fuel. This is particularly true for nonbuoyant flames where residence times vary considerably with varying burner diameter for a given flame 
length, in contrast to buoyant flames where flame lengths and residence times are closely correlated $[9,12,13]$. Laminar smoke point residence times (defined as the time between termination of fuel flow into the base of the flame and the disappearance of all flame luminosity) have been measured directly for buoyant flames [12, 13]. Similar results were not available, however, for the present nonbuoyant flames. Thus, the residence times for the nonbuoyant flames were found using a computational simulation. For these computations, the flame residence time was defined as the time required for a fluid parcel to convect along the flame axis from the burner exit to the flame sheet.

Details concerning the flame structure predictions are provided in Ref. 18. The major assumptions of the simulations are as follows: steady laminar axisymmetric flow, constant radiative heat loss fraction of the chemical energy release for all parts of the flame, the laminar flamelet approximation for all scalar properties (which requires the previous radiation approximation and implies equal binary diffusivities of all species, negligible thermal diffusion and unity Lewis number), small flame standoff distance at points of flame attachment, constant property ambient environment, ideal gas mixture with negligible soot volumes and a constant Prandtl/Schmidt number, and multicomponent mixing laws for the mixture viscosity. The state relationships for gas species concentrations as a function of mixture fraction were found from correlations of measurements within buoyant laminar diffusion flames $[22,23]$. The corresponding state relationships for temperature were computed given the state relationships for major gas species and the radiative heat loss fraction, as described in Ref. 23. Following the recommendation of Edelman and Bahadori [24], the full elliptic governing equations were solved for the present low Reynolds number flames, rather than adopting the boundary layer approximations.

The flame structure predictions were evaluated using measured flame shapes and lengths. The predictions were in reasonably good agreement (within $15 \%$ ) with measured flame lengths reported by Haggard and Cochran [25] for nonbuoyant ethylene-air flames at atmo- spheric pressure and having various Reynolds numbers. Flame shape predictions for weakly buoyant ethylene and acetylene-air flames at various pressures and burner exit Reynolds numbers also were satisfactory (within 10\%) [18]. Thus although additional evaluation of the structure predictions would be desirable, the approach should provide adequate estimates of residence times for present purposes.

Predictions of flame residence times, $t_{r}$, for nonbuoyant laminar jet flames are illustrated in Figs. 2 and 3, in order to assist the interpretation of the laminar smoke point measurements. These results are for ethylene-air flames, at a pressure, $p=1 \mathrm{~atm}$; findings for propane-air flames are essentially the same. Additionally, residence times are roughly proportional to pressure for a given flame length, $L$ [18]. The results illustrated in Fig. 2 show that increasing flame lengths for a fixed burner exit diameter, $d$, yield progressively increasing residence times. This behavior is similar to buoyant flames, where residence times are proportional to the square root of the flame length $[9,12,13]$. However, this behavior differs from constant-property estimates of residence times for nonbuoyant flames based on the boundary layer approximations, where residence times are independent of the flame length and only vary with the burner diameter $[9,19]$. This

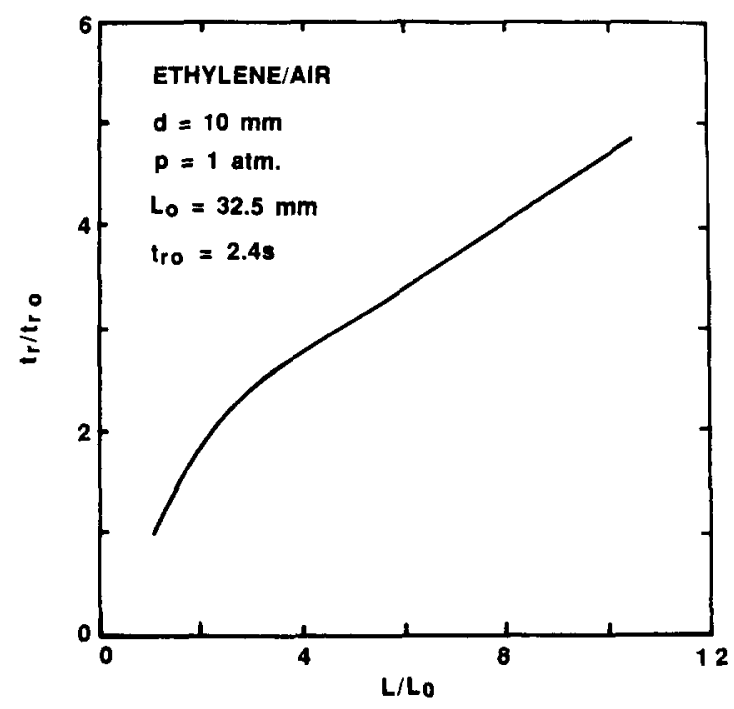

Fig. 2. Predicted flame residence times as function of flame length for nonbuoyant ethylene-air laminar jet diffusion flames. 


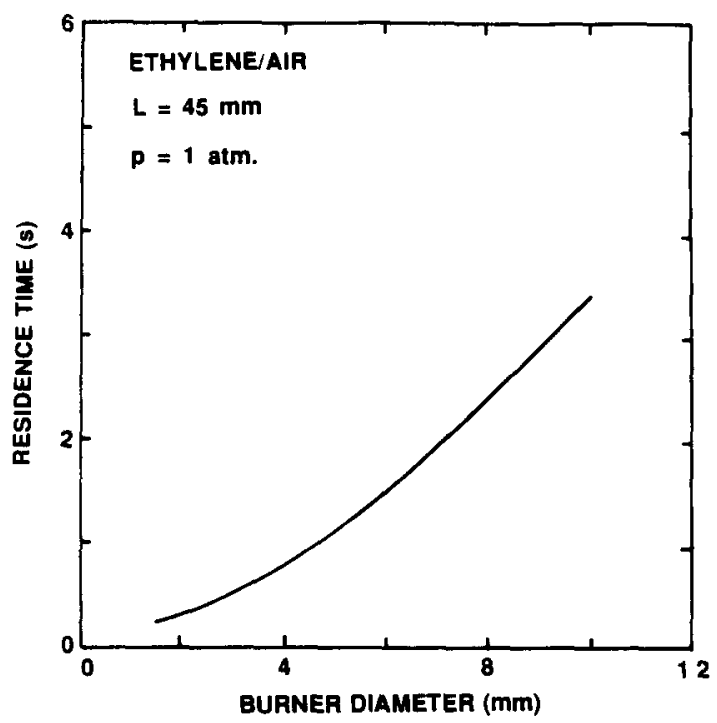

Fig. 3. Predicted flame residence times as function of burner diameter for nonbuoyant ethylene-air laminar jet diffusion flames.

difference primarily is caused by effects of diffusion in the streamwise direction.

The results illustrated in Fig. 3 show that residence times increase with increasing burner diameter for a fixed flame length. This behavior also is observed for boundary layer treatments of nonbuoyant laminar jet diffusion flames and is caused by reduced flow velocities at the burner exit as the burner diameter is increased for a fixed flame length [19]. This behavior, however, differs from buoyant laminar jet diffusion flames where residence times largely are a function of flame length, and are relatively independent of burner diameter and exit velocity because buoyancy largely controls flow velocities within these flames $[9,19]$.

\section{EXPERIMENTAL RESULTS AND DISCUSSION}

Laminar smoke point luminosity lengths for ethylene and propane diffusion flames are summarized in Table 1. Results for nonbuoyant flames come from the present measurements at pressures of $0.5,1.0$, and $2.0 \mathrm{~atm}$ and burner exit diameters of 1.6, 2.7, and $5.9 \mathrm{~mm}$. Results for buoyant flames come from the measurements of Refs. 5 and 12 at atmospheric pressure for a burner exit diameter of roughly $10 \mathrm{~mm}$, although effects of burner
TABLE 1

Laminar Smoke Point Luminosity Lengths $(\mathrm{mm})^{a}$

\begin{tabular}{|c|c|c|c|}
\hline \multirow{2}{*}{ Burner Diameter (mm) } & \multicolumn{3}{|c|}{ Pressure (atm) } \\
\hline & 0.5 & 1.0 & 2.0 \\
\hline \multicolumn{4}{|c|}{ Ethylene-Air Flames } \\
\hline \multicolumn{4}{|l|}{ Nonbuoyant } \\
\hline 1.6 & 85 & 36 & -. \\
\hline 2.7 & 80 & 25 & 13 \\
\hline 5.9 & 110 & 28 & 13 \\
\hline \multicolumn{4}{|l|}{ Buoyant $[5,12]$} \\
\hline 10.0 & - & $106-135$ & - \\
\hline \multicolumn{4}{|c|}{ Propane-Air Flames } \\
\hline \multicolumn{4}{|l|}{ Nonbuoyant } \\
\hline 1.6 & 130 & 42 & 16 \\
\hline 2.7 & 140 & 38 & 18 \\
\hline 5.9 & 130 & 42 & 20 \\
\hline \multicolumn{4}{|l|}{ Buoyant $[5,12]$} \\
\hline 10.0 & - & $162-169$ & - \\
\hline
\end{tabular}

${ }^{a}$ Determined from present measurements for round laminar jet diffusion flames in still air at low-gravity for nonbuoyant flames, and from Schug et al. [5] and Sivathanu and Faeth [12] for round laminar jet diffusion flames in coflowing air at normal gravity for buoyant flames.

diameter on the laminar smoke point properties of buoyant flames are small, as noted earlier.

There are several interesting features of the measurements summarized in Table 1. First, the nonbuoyant flames do exhibit laminar smoke point luminosity lengths, in contrast to the conjecture that these lengths would not exist because nonbuoyant flames have residence times that are independent of flame length under the boundary layer approximations [9]. The latter behavior does not occur because streamwise diffusion causes residence times to increase as flame lengths are increased, leading to conditions where the flames emit soot as discussed in connection with Fig. 2. Next, the laminar smoke point luminosity lengths of nonbuoyant flames exhibit little variation with burner diameter, which is similar to findings for buoyant flames [13]. This behavior is expected for buoyant flames because their residence times largely are functions of flame lengths. Similar behavior was not expected for nonbuoyant flames, however, because their residence times increase with increasing burner diameter for a given flame length, see Fig. 3. Additionally, laminar smoke point luminosity 
lengths are roughly four times smaller for nonbuoyant flames than buoyant flames at otherwise comparable conditions. On the other hand, laminar smoke point residence times are much longer for nonbuoyant than buoyant flames, for example, 200-1500 ms for nonbuoyant flames at atmospheric pressure, based on the predictions discussed in connection with Figs. 2 and 3 , in comparison to $40-50 \mathrm{~ms}$ for the same fuels in buoyant flames [12].

Other properties of the laminar smoke point luminosity lengths summarized in Table 1 are qualitatively similar for nonbuoyant and buoyant flames. For example, laminar smoke point luminosity lengths are slightly longer for propane than for ethylene in both cases. Additionally, the pressure variation of laminar smoke point luminosity lengths for buoyant flames found by Flower and Bowman [10], $\sim p^{-1.3}$, agrees with trends of present measurements for nonbuoyant flames with an average error of $25 \%$. This quantitative agreement probably is somewhat fortuitous, however, due to the different soot paths in buoyant and nonbuoyant flames discussed earlier. Nevertheless, the reduction of laminar smoke point luminosity lengths with increasing pressure is consistent with increased residence times at higher pressures for nonbuoyant flames, with effects of pressure on reaction rates being a contributing factor.

The reasons for the differences between the laminar smoke point properties of the nonbuoyant and buoyant laminar jet diffusion flames are not quantitatively understood at present. However, the two general phenomena discussed earlier-differences in the soot paths and differences in the velocity distribution along the soot paths for nonbuoyant and buoyant flames-play a role in this behavior. Different sites for initial soot nucleation and different conditions for subsequent soot nucleation and growth, should lead to different maximum primary particle sizes for nonbuoyant and buoyant flames of comparable length. The longer soot oxidation period relative to the soot nucleation and growth period for nonbuoyant flames in comparison to buoyant flames, due to the different velocity distributions along soot paths, also provides a mechanism for increased residence times prior to soot emission for the nonbuoyant flames, as observed during the present investigation. Finally, the longer residence times of nonbuoyant flames should enhance radiation heat losses, with corresponding temperature variations altering the reactive environment of soot as well.

In view of these differences in soot paths and flow structure it is not surprising that the soot emission properties of nonbuoyant and buoyant jet diffusion flames are different. It also is clear that nonbuoyant jet diffusion flames provide an interesting new perspective to gain a better understanding of soot mechanisms in diffusion flame environments.

This research was sponsored, in part, by NASA Grant No. NAG3-1245. The assistance of J. B. Mullins, of NASA Marshall Space Flight Center, and D. G. Gotti, H. D. Ross, R. G. Sotos and D. P. Stocker, all of the NASA Lewis Research Center, is gratefully acknowledged. The authors also would like to thank a reviewer for pointing out the similar pressure variations of the laminar smoke point luminosity lengths of buoyant and nonbuoyant flames.

\section{REFERENCES}

1. Clarke, A. E., Hunter, T. C., and Garner, F. H., J. Inst. Petrol. 32:627-642 (1946).

2. Schalla, R. L., Clark, T. P., and McDonald, G. E., NACA Report 1186, 1954.

3. Schalla, R. L., and McDonald, G. E. Fifth Symposium (International) on Combustion, The Combustion Institute, Pittsburgh, 1954, p. 316.

4. Schalla, R. L., and Hubbard, R. R., NACA Report 1300, 1959.

5. Schug, K. P., Manheimer-Timnat, Y., Yaccarino, P., and Glassman, I., Combust. Sci. Technol. 22:235-250 (1980).

6. Glassman, I., and Yaccarino, P., Eighteenth Symposium (International) on Combustion, The Combustion Institute, Pittsburgh, 1980, p. 1175.

7. Glassman, I., and Yaccarino, P., Combust. Sci. Technol. 24:107-114 (1980).

8. Gomez, A., Sidebotham, G., and Glassman, I., Combust. Flame 58:45-57 (1984).

9. Glassman, I., Twenty-Second Symposium (International) on Combustion, The Combustion Institute, Pittsburgh, 1988, p. 295.

10. Flower, W. L., and Bowman, C. T., Twenty-First Symposium (International) on Combustion, The Combustion Institute, Pittsburgh, 1986, p. 1115. 
11. Markstein, G. H., Twenty-Second Symposium (International) on Combustion, The Combustion Institute, Pittsburgh, 1988, p. 363.

12. Sivathanu, Y. R., and Faeth, G. M., Combust. Flame 81:133-149 (1990).

13. Köylï, Ü. Ö., and Faeth, G. M., Combust. Flame 87:61-76 (1991)

14. Faeth, G. M., Proceedings of the ALAA/IKI Microgravity Science Symposium - Moscow, AIAA, Washington, 1991, p. 281.

15. Santoro, R. J., Semerjian, H. B., and Dobbins, R. A., Combust. Flame 51:203-218 (1983).

16. Santoro, R. J., and Semerjian, H. G., Twentieth Symposium (International) on Combustion, The Combustion Institute, Pittsburgh, 1984, p. 997.

17. Santoro, R. J., Yeh, T. T., Horvath, J. J., and Semerjian, H. G., Combust. Sci. Technol. 53:89-115 (1987).

18. Mortazavi, S., Sunderland, P. B., Jurng, J., Köylü,
Ü. Ö., and Faeth, G. M., AIAA Paper No. 93-0708, 1993.

19. Spalding, D. B., Combustion and Mass Transfer, Pergamon, New York, 1979, Chap. 10.

20. Spengler, G., and Kern, J., Brennst. Chem. 50:321-324 (1969).

21. Boedecker, L. R., and Dobbs, G. M., Combust. Sci. Technol. 46:301-323 (1986).

22. Gore, J. P., and Faeth, G. M., Twenty-First Symposium (International) on Combustion, The Combustion Institute, Pittsburgh, 1986, p. 1521.

23. Sivathanu, Y. R., and Faeth, G. M., Combust. Flame 82:211-230 (1990).

24. Edelman, R. B, and Bahadori, M. Y., Acta Astronaut. 13:681-688 (1986).

25. Haggard, J. B., Jr., and Cochran, T. H., Combust. Sci. Technol. 5:291-298 (1972).

Received 11 February 1993; revised 16 July 1993 